\title{
Tunnel technique with connective tissue graft versus coronally advanced flap with enamel matrix derivative for root coverage: a RCT using 3D digital measuring methods. Part II. Volumetric studies on healing dynamics and gingival dimensions
}

\author{
Rebele, Stephan F ; Zuhr, Otto ; Schneider, David ; Jung, Ronny E ; Hürzeler, Markus B
}

\begin{abstract}
AIM: The aim of this randomized clinical trial (RCT) was to compare the clinical performance of the tunnel technique with subepithelial connective tissue graft (TUN) versus a coronally advanced flap with enamel matrix derivative (CAF) in the treatment of gingival recession defects. The use of innovative 3D digital measuring methods allowed to study healing dynamics at connective tissue (CT)-grafted sites and to evaluate the influence of the thickness of the root covering soft tissues on the outcome of surgical root coverage. MATERIAL METHODS: Twenty-four patients contributed a total of 47 Miller class I or II recessions for scientific evaluation. Precise study models collected at baseline and follow-up examinations were optically scanned and virtually superimposed for digital evaluation of clinical outcome measures including mean marginal soft tissue thickness (THK). Healing dynamics were measured in a defined region of interest at CT-grafted sites where volume differences between time points were calculated. RESULTS: At 12 months, recession reduction as well as mean root coverage were significantly better at CT-grafted sites treated in the TUN group (1.94 $\mathrm{mm}$ and $98.4 \%$ respectively) compared to the non-augmented sites of the CAF group ( $1.17 \mathrm{~mm}$ and $71.8 \%$ respectively) and statistical analysis revealed a positive correlation of THK $(1.63 \mathrm{~mm}$ TUN versus $0.91 \mathrm{~mm} \mathrm{CAF,}<<0.0001)$ to both these variables. Soft tissue healing following surgical root coverage with CT-grafting was mainly accomplished after 6 months, with around two-thirds of the augmented volume being maintained after 12 months. CONCLUSIONS: The TUN resulted in thicker gingiva and better clinical outcomes compared to CAF. Increased gingival thickness was associated with better surgical outcomes in terms of recession reduction and root coverage.
\end{abstract}

DOI: https://doi.org/10.1111/jcpe.12254

Posted at the Zurich Open Repository and Archive, University of Zurich ZORA URL: https://doi.org/10.5167/uzh-96537

Journal Article

Originally published at:

Rebele, Stephan F; Zuhr, Otto; Schneider, David; Jung, Ronny E; Hürzeler, Markus B (2014). Tunnel technique with connective tissue graft versus coronally advanced flap with enamel matrix derivative for root coverage: a RCT using 3D digital measuring methods. Part II. Volumetric studies on healing dynamics and gingival dimensions. Journal of Clinical Periodontology, 41(6):593-603.

DOI: https://doi.org/10.1111/jcpe.12254 
Received Date : 17-Sep-2013

Revised Date : 10-Mar-2014

Accepted Date : 27-Mar-2014

Article type $\quad$ : Randomized Clinical Trial

Tunnel technique with connective tissue graft versus coronally advanced flap with enamel matrix derivative for root coverage: a RCT using $3 \mathrm{D}$ digital measuring methods. Part II. Volumetric studies on healing dynamics and gingival dimensions

Stephan F. Rebele ${ }^{1,2}$

Otto Zuhr ${ }^{1,3}$

David Schneider ${ }^{4}$

Ronny E. Jung ${ }^{4}$

Markus B. Hürzeler ${ }^{1,2}$

1 Private Office Huerzeler/Zuhr, Munich, Germany

2 Department of Operative Dentistry and Periodontology, University School of Dentistry, Albert Ludwigs University, Freiburg, Germany

3 Department of Periodontology, Center for Dental, Oral and Maxillofacial Medicine (Carolinum), Johann Wolfgang Goethe University, Frankfurt/Main, Germany

4 Clinic of Fixed and Removable Prosthodontics and Dental Material Science, Center of Dental Medicine, University of Zurich, Switzerland

This article has been accepted for publication and undergone full peer review but has not been through the copyediting, typesetting, pagination and proofreading process, which may lead to differences between this version and the Version of Record. Please cite this article as doi: $10.1111 /$ jcpe. 12254

This article is protected by copyright. All rights reserved. 


\title{
Corresponding author / Address:
}

\author{
Stephan Rebele \\ Private Office Huerzeler/Zuhr \\ Rosenkavalierplatz 18 \\ 81925 Munich \\ Germany \\ Phone: $\quad+49891891750$ \\ Fax: $\quad+498918917528$ \\ E-mail: s.rebele@ huerzelerzuhr.com
}

\section{Key words:}

Root coverage; subepithelial connective tissue graft; gingival thickness; soft tissue volume; volumetric measurements;

\section{Running title:}

TUN vs. CAF for root cov: RCT. Part II

\section{ABSTRACT}

Aim: The aim of this randomized clinical trial $(R C T)$ was to compare the clinical performance of the tunnel technique with subepithelial connective tissue graft (TUN) vs. a coronally advanced flap with enamel matrix derivative (CAF) in the treatment of gingival recession defects. The use of innovative 3D digital measuring methods allowed to study healing dynamics at connective tissue (CT) grafted sites and to evaluate the influence of the thickness of the root covering soft tissues on the outcome of surgical root coverage.

Material \& Methods: 24 patients contributed a total of 47 Miller class I or II recessions for scientific evaluation. Precise study models collected at baseline and follow-up examinations were optically scanned and virtually superimposed for digital evaluation of clinical outcome measures including mean marginal soft tissue thickness (THK). Healing dynamics were measured in a defined region of interest at CT-grafted sites where volume differences between time points were calculated.

This article is protected by copyright. All rights reserved. 
Results: At 12 months, recession reduction as well as mean root coverage were significantly better at CT-grafted sites treated in the TUN group $(1.94 \mathrm{~mm}$ and $98.4 \%$, respectively) compared to the non-augmented sites of the CAF group $(1.17 \mathrm{~mm}$ and $71.8 \%$, respectively) and statistical analysis revealed a positive correlation of THK $(1.63 \mathrm{~mm}$ TUN versus $0.91 \mathrm{~mm}$ CAF, $p<0.0001$ ) to both these variables. Soft tissue healing following surgical root coverage with CT-grafting was mainly accomplished after 6 months, with around $2 / 3$ of the augmented volume being maintained after 12 months.

Conclusions: TUN resulted in thicker gingiva and better clinical outcomes compared to CAF. Increased gingival thickness was associated with better surgical outcomes in terms of recession reduction and root coverage.

\section{Conflict of interest and source of funding statement}

The authors declare that they have no conflict of interests. The study was self-funded by the authors and their institution.

\section{Clinical Relevance}

Scientific rationale for the study. The real significance of the thickness of the root covering soft tissues has still not been entirely clarified. This study used 3D digital measuring methods to study healing dynamics at CT-grafted sites and to evaluate the influence of the thickness of the root covering soft tissues on the outcome of surgical root coverage.

Principal findings: Increased gingival thickness was associated with better surgical outcomes in terms of recession reduction and root coverage.

Practical implications: The findings of this study suggest that particularly sites of thinner gingival biotypes seem to benefit from some minor gingival thickening during surgical root coverage. The data indicate that the use of rather reasonably sized, thin CTGs seems to be suitable in order to obtain a suggested mean marginal soft tissue thickness of around $1.5 \mathrm{~mm}$ after surgery. Soft tissue healing following surgical root coverage with CT grafting is mainly accomplished after 6 months.

The ultimate goal of root coverage procedures is the complete coverage of the recession defect, with nice aesthetics and harmonious integration of the covering tissues and with minimal probing depths after treatment (Cairo et al., 2008). The process of clinical decision-

This article is protected by copyright. All rights reserved. 
making and thus the search for the most contemporary and best available treatment modality to achieve these aforementioned criteria of success represents one of the major challenges in the field of plastic periodontal surgery today (Cortellini and Pini Prato, 2012).

Several studies have been correlating greater flap thickness to better clinical outcomes after root coverage und thus identified flap thickness as one relevant prognostic factor in the treatment of gingival recession defects (Hwang and Wang, 2006). It was demonstrated that $0.8 \mathrm{~mm}$ is to be considered as the critical flap thickness above which complete root coverage can be expected in Miller class I and II recession type defects when using a coronally advanced flap (CAF) alone (Baldi et al., 1999). Although there seems to be a general consensus in the scientific community that additional thickening of the marginal gingiva with the use of autologous connective tissue grafts (CTG) can further enhance treatment outcomes and particularly improve the long-term prognosis of the results (Cortellini and Pini Prato, 2012), the written evidence is still inconsistent in this context: while single studies could not demonstrate any statistically significant differences over time between CAF procedures either with or without the use of a CTG (Wennstrom and Zucchelli, 1996), other investigations showed a clear tendency to recession recurrence at sites without adjunctive CTG application - in the short-term (Cortellini et al., 2009) as well as in the long-term (Nickles et al., 2010, Pini-Prato et al., 2010).

As harvesting of a CTG adds additional morbidity to any surgical root coverage procedure (Cairo et al., 2008, Chambrone et al., 2010), it is indispensable, however, to clarify the clinical relevance and long-term benefit of the combined procedure on a scientific basis. It is beyond all doubt that more transparency and understanding in this context will substantially influence future research and clinical developments, in particular against the background of an ever-increasing field of biomaterial science, which continuously launches improved products that aim to substitute the use of autologous grafts (Zuhr et al., in press). Further progress with regard to gingival recession treatment will, to some extent, therefore be dependant on whether or not some fundamental landmark questions can be answered: How thick is the marginal gingiva in the area of the formerly exposed root surface after root coverage either with or without CTG application? Does an increased thickness of the root covering soft tissues improve the treatment outcome? How long is the healing process with regard to soft tissue volume changes and how extensive are these changes? Is there any critical soft tissue thickness above which no further benefit is to be seen for the patient? Is there any correlation between marginal soft tissue thickness and the stability of the gingival margin's position over time?

The present paper does not make any claim to be able to entirely answer all these aforementioned, important questions. With the introduction of an innovative new measuring This article is protected by copyright. All rights reserved. 
method for evaluating the outcomes after surgical root coverage, however, this study promises to make another small step towards further understanding in this field. The aim of this randomized clinical trial (RCT) was therefore (1) to examine three-dimensional soft tissue aspects following root coverage with either the tunnel technique with subepithelial connective tissue graft (TUN) or the coronally advanced flap with enamel matrix derivative (CAF) and (2) to incorporate the findings of these volumetric studies in a global context with regard to gingival recession treatment.

\section{MATERIAL AND METHODS}

The present article is reported in accordance with the CONSORT 2010 statement for improving the quality of reporting on randomized controlled trials (http://www.consortstatement.org) (Schulz et al., 2010, Moher et al., 2010).

\section{Study design and ethics committee approval}

The study was designed as a single-centre, randomized, clinical trial on the treatment of single and multiple gingival recession defects. A combined parallel group / split-mouth set up was used and two different treatment modalities were assessed: the tunnel technique with subepithelial connective tissue graft (TUN) and the coronally advanced flap with enamel matrix derivative (CAF). Clinical and patient-centered outcomes, including final aesthetic outcomes, are reported in the first part of this article series (Zuhr et al., 2013). The present article focuses on the findings of volumetric evaluations after root coverage therapy.

The study protocol was approved by the University of Freiburg Ethics Committee (Ethics Committee No.: 148/09) and registered in the German Clinical Trials Register (DRKS-ID: DRKS00003285). All participants signed an informed consent. In obtaining the informed consent and in conducting the study, the principles outlined in the Declaration of Helsinki, as revised in 2000 , were followed.

\section{Participants}

\section{Patient enrolment and study inclusion criteria}

Patients were enrolled at the Private Office of Huerzeler/Zuhr, Munich, Germany between July 2009 and June 2011. Patients were non-smokers, systemically and periodontally healthy, and presented each with at least one Miller class I or II gingival recession defect This article is protected by copyright. All rights reserved. 
(Miller, 1985). Recessions were only considered at upper incisors, canines and pre-molars, and only when presenting with a clearly identifiable, natural Cemento-Enamel Junction (CEJ). Please see Zuhr et al. for more details regarding inclusion / exclusion criteria (Zuhr et al., 2013).

Each patient contributed with at least one single gingival recession defect. When patients presented with multiple adjacent gingival recessions, a multiple recession treatment was applied and all defects meeting the inclusion criteria were used for data collection. If applicable, patients were treated with both procedures in the maxilla by means of a splitmouth design.

\section{Sample size calculation}

The needed number of patients to be treated in this study was 12 for the test group (TUN) and 12 for the control group (CAF). However, to allow for possible dropouts, a total of 15 patients were recruited in each of two groups (Zuhr et al., 2013).

\section{Investigators and Institutions}

All surgical procedures were done by the same expert operator (O.Z.) with a longstanding experience in periodontal plastic surgery. Clinical interventions were performed at the Private Office of Huerzeler/Zuhr, Munich, Germany.

This study used three-dimensional digital measuring methods. One examiner (D.S.), blinded with respect to the surgical procedures, performed all these digital measurements. Having an expertise in computerized dentistry and being highly experienced with the applied measuring technique, this examiner evaluated dimensional soft tissue alterations including measurements of recession depth (REC) and mean marginal soft tissue thickness (THK). Digital measurements were performed at the Clinic of Fixed and Removable Prosthodontics and Dental Material Science, Center of Dental Medicine, University of Zurich, Switzerland.

Statistical analysis was performed at the Institute of Medical Biometry and Medical Informatics, Albert-Ludwigs-University, Freiburg, Germany.

\section{Interventions}

\section{Data collection}

Data collection included digital measurements at baseline, 6 months and 12 months. In addition to this general protocol, a small cohort of 6 patients in the test group (TUN) underwent a further close-meshed follow-up in order to monitor healing dynamics following This article is protected by copyright. All rights reserved. 
root coverage with $\mathrm{CT}$ grafting. In those patients, additional evaluations with digital measurements were undertaken at 1, 2 and 3 months.

\section{Digital measurements at baseline, 6 and 12 months}

Digital measurements were based on an optical 3D measurement system. To this purpose, precise study models were made out of dental stone (Esthetic-base ${ }^{\circledR}$ Gold, Dentona, Dortmund, Germany) utilizing impressions taken of the surgically treated sites at baseline

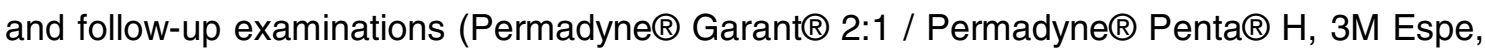
Neuss, Germany). All models were digitized with a lab-side optical scanner (Imetric D103®, Imetric 3D GmbH, Courgenay, Switzerland). The acquired data were saved as digital surface models in surface tessellation language (stl) file format and transferred into a digital imaging software (Swissmeda software / Smop, Swissmeda, Zurich, Switzerland). Baseline and corresponding follow-up scans of each clinical case were then virtually superimposed and matched into one common coordinate system. By using the buccal surfaces of the concerned teeth as reference points for the superpositioning of the different time-points, this approach allowed for precise evaluation of dimensional soft tissue alterations over time (Fig. 1).

REC was measured from CEJ to the gingival margin in a cross-section at the central buccal site (data first published in (Zuhr et al., 2013)). THK was measured as mean thickness of the marginal soft tissues surgically established above the formerly exposed root surface. To this purpose, an individually defined area of interest was measured above each former recession defect and the volume difference between time-points was quantified. The measured area was located in the attached gingiva above the formerly exposed root surface, exhibited a polygonal shape and kept a distance of $1 \mathrm{~mm}$ to the pre- and post-operative lining of the margo gingivae. THK was then calculated as the measured volume gain per measured area $\left(\mathrm{THK}[\mathrm{mm}]=\mathrm{vol}\left[\mathrm{mm}^{3}\right] /\right.$ area $\left.\left[\mathrm{mm}^{2}\right]\right)$. REC and THK measurements were recorded to the nearest $0.01 \mathrm{~mm}$.

\section{Digital measurements to monitor healing dynamics at CT grafted sites}

The study also aimed to monitor healing dynamics by means of observing volumetric alterations of the soft tissues following surgical root coverage with concomitant CT grafting. In this context, patients with TUN-treated sites were asked to voluntarily attend a further close-meshed follow-up with additional evaluations and digital measurements performed at 1, 2 and 3 months. In these cases, the virtually superimposed image finally consisted of 6 overlying baseline and corresponding follow-up scans matched into one common coordinate This article is protected by copyright. All rights reserved. 
system. This allowed for detailed evaluation of soft tissue volumetric alterations in the course of healing. A predefined area of interest was measured at each recessed area and the volume difference between time points was calculated (vol $\left.\left[\mathrm{mm}^{3}\right]\right)$. Due to an individually varying size of the CTG, the measured area varied between the sites, but was kept constant at one site over time. The region of interest featured a polygonal shape and covered the graft's extensions in the attached gingiva of the formerly recessed area. In order to allow for a direct comparison of the different sites, absolute values of volumetric alterations (vol $\left[\mathrm{mm}^{3}\right]$ ) were converted in relative sizes (vol [\%]) with the postoperative volume gain at 1 month being regarded as the baseline value of soft tissue augmentation (100\%). A total of 6 patients agreed to participate in this protocol of a further close-meshed follow-up.

\section{Pre-surgical preparations}

Cause-related therapy was completed in all participants prior to surgery. This included detailed oral hygiene instructions as well as dental prophylaxis and low-abrasive airpolishing. Patients were particularly instructed to a non-traumatizing brushing technique using a soft toothbrush in order to eliminate wrong habits associated with the aetiology of gingival recessions.

\section{Surgical procedures}

Each experimental site was randomly assigned to one of the two experimental procedures. A coronally advanced flap with enamel matrix derivative application (CAF) served as the control procedure, which was compared to the tunnel technique with subepithelial connective tissue graft (TUN) as being the test procedure. Please see Zuhr et al. for more information regarding randomization and allocation concealment as well as for a detailed description of the surgical proceedings (Zuhr et al., 2013).

In brief description, CAF treatment was performed by starting with two c-shaped, divergent releasing incisions lateral to the recessed area. Marginal incisions were made to unite the releasing incisions and a split-thickness flap was raised beyond the mucogingival junction (MGJ). The papillae adjacent to the involved teeth were de-epithelialized and the exposed root surfaces were treated with preconditioning EDTA (Straumann $®$ PrefGel) and with enamel matrix derivative (Straumann $\circledast$ Emdogain) according to the manufacturer's instructions (Institute Straumann AG, Basel, Switzerland). Sling sutures were placed to stabilize the flap in a coronal position about 1-2 $\mathrm{mm}$ above the CEJ (Seralene $®$ 6.0, Serag-

This article is protected by copyright. All rights reserved. 
Wiessner KG, Naila, Germany), followed by interrupted sutures to close the releasing incisions (Seralene® 7.0).

TUN treatment was performed basically in accordance with the descriptions on a modified microsurgical tunnel technique by Zuhr (Zuhr et al., 2007). Following initial sulcular incisions, tunnelling knives were used to undermine the buccal gingiva by means of a split-thickness flap preparation, aiming to create a continuous tunnel in the buccal soft tissues of the recessed area. Flap preparation was extended well into the mucosa and adjacent papillary tissues were carefully detached by means of a full-thickness preparation in order to gain sufficient flap mobility. A connective tissue graft harvested from the palate was trimmed to a thickness of $1-1.5 \mathrm{~mm}$ and inserted into the tunnel. Double-crossed sutures (Seralene $₫$ 6.0) were applied to stabilize the buccal soft tissue complex in a coronal position about 1-2 mm above the CEJ (Zuhr et al., 2009).

\section{Post-surgical protocol}

Patients were instructed to avoid any mechanical trauma or tooth brushing in the surgical sites for 2 weeks. Analgesic-antiphlogistic medication (ibuprofen) was prescribed as required and patients were instructed to rinse with Chlorhexidine three times per day for 2 weeks. Sutures were removed after 7 days. Two weeks after surgery, patients resumed mechanical tooth cleaning with a soft toothbrush. Patients were recalled at 1, 3, 6 and 12 months for professional oral hygiene procedures.

\section{Statistical analysis}

Statistical analysis was done with SAS version 9.1.2 (SAS Institute Inc., Cary, NC, USA). Descriptive statistics were performed using mean values, standard deviations, frequencies and percentages. A patient-level analysis was performed for each parameter, regarding the experimental site as the statistical unit. In doing so, means for each patient and treatment assignment were calculated from the parameters measured at the recession sites at different time-points. The significance of the differences between the groups was evaluated using Wilcoxon-Mann-Whitney test (two-sided, t-approximation) and Fisher's exact test, respectively. Differences were considered statistically significant for $p$-values $<0.05$. The Pearson's correlation coefficient $r$ was calculated with the study's complete 12-month data set to examine the relationship between THK and REC reduction and between THK and \% root coverage, respectively. Moreover, a linear regression analysis was performed to assess the relationship between THK and REC reduction and a logistic model was calculated with This article is protected by copyright. All rights reserved. 
complete root coverage being the target variable and mean marginal soft tissue thickness being the covariable. The linear regression analysis as well as the logistic model were both based on a tooth-level analysis of the concerned parameters but accounted for repeated measurements (multiple recessions) per patient.

\section{RESULTS}

\section{Experimental population}

24 patients (17 females, 7 males) were recruited und treated between October 2010 and June 2011. The mean age was $37.9 \pm 9.8$ years (21-55 years). 6 patients were treated with both procedures by means of a split-mouth design, so that finally a total of 30 experimental sites (15 per experimental group) contributed a total of 47 recession defects for scientific evaluation (for a CONSORT flow diagram of the study, please see (Zuhr et al., 2013)). Two patients in the CAF group were not able to keep the 6-months follow-up examination, but both of them were available at the 12-months follow-up again. Moreover, one patient of the split-mouth-cases was not able to comply with the recall for the 12-months follow-up. All 6 patients participating in the further close-meshed follow-up to monitor healing dynamics at CT grafted sites did not miss any of their examinations.

\section{Defect characteristics at baseline - recession reduction, root coverage and marginal soft tissue thickness at 6 and 12 months}

Table 1 depicts descriptive statistics for the measured parameters of recession depth (REC) and mean marginal soft tissue thickness (THK) at baseline, 6 and 12 months. The comparison of TUN and CAF for variables of recession depth (REC) reduction $(\mathrm{mm}), \%$ root coverage $(\mathrm{RC})$ and \% defects with complete root coverage (CRC) 6 and 12 months after surgery is reported in Table 2 (data first published in (Zuhr et al., 2013)).

The TUN group consisted of 24 recession defects (15 experimental sites in 12 patients) with a baseline recession depth of $1.93 \pm 0.57 \mathrm{~mm}(1.06-2.89 \mathrm{~mm})$. In the CAF group (15 experimental sites in 12 patients) a total of 23 recession defects with a baseline recession depth of $1.69 \pm 0.63 \mathrm{~mm}(0.94-3.48 \mathrm{~mm})$ was treated.

At the 12-months follow-up, RC was on average $98.4 \pm 3.6 \%$ for the TUN group and $71.8 \pm$ $20.3 \%$ for the CAF group $(p=0.0004)$. REC reduction amounted to $1.94 \pm 0.57 \mathrm{~mm}$ at TUNtreated sites (corresponding to a mean residual recession of $0.04 \pm 0.07 \mathrm{~mm}$ after 12 months), whereas $1.17 \pm 0.42 \mathrm{~mm}$ of REC reduction (corresponding to a mean residual This article is protected by copyright. All rights reserved. 
recession depth of $0.55 \pm 0.49 \mathrm{~mm}$ ) was recorded in the CAF group $(p=0.0015)$. CRC was detected in 11 out of 14 experimental sites (78.6\%) analysed at 12 months in the TUN group and in 3 out of $14(21.4 \%)$ of CAF-treated sites $(p=0.007)$. The measured THK after 12 months was $1.63 \pm 0.42 \mathrm{~mm}$ at TUN-treated sites, compared to $0.91 \pm 0.18 \mathrm{~mm}$ at sites having received CAF treatment $(p<0.0001)$.

\section{The relationship of marginal soft tissue thickness to recession reduction and root coverage}

Various analyses were undertaken to investigate the relationship between marginal soft tissue thickness and both recession depth reduction as well as mean root coverage. Based on the study's complete data-set, the calculated Pearson's correlation coefficient indicated a positive correlation between THK and REC reduction after 12 months $(r=0.6194)$. Moreover, a linear regression analysis was performed to assess the relationship between these variables: this analysis showed a significant linear relation between THK and REC reduction after 12 months $(p=0.006)$ (Fig. 2).

Regarding the correlation of THK and \% RC after 12 months, a calculated Pearson's correlation coefficient of $r=0.6166$ revealed a positive correlation of those two variables, too. However, the measured data indicated a certain soft tissue thickness above which additional thickening seemed not worthwhile with regard to the surgical outcome. Therefore, a logistic model was calculated with complete root coverage being the target variable and mean marginal soft tissue thickness being the covariable. This analysis assumed a mean THK of $1.44 \mathrm{~mm}$ to be necessary for achieving CRC with a confidence of 95\% (Fig. 3).

\section{Healing dynamics at CT grafted sites}

The results of volumetric evaluations performed in a cohort of 6 patients in order to monitor healing dynamics following CT grafting at TUN-treated sites are presented in Table 3 and Fig. 4. With the post-operative volume gain at 1 month being regarded as baseline value of soft tissue augmentation (100\%), treated sites showed a mean shrinkage of $1 / 4$ of the augmented volume after 3 months, amounting to $1 / 3$ after 12 months (corresponding to a mean maintenance of $74 \%$ of the augmented volume after 3 months and $64 \%$ after 12 months, respectively). With regard to post-operative soft tissue volume changes, the healing process seemed to be accomplished after 6 months.

This article is protected by copyright. All rights reserved. 


\section{DISCUSSION}

A long-standing debate in the scientific community relates to the aspect of the thickness of the root covering tissues following surgical root coverage (Wennstrom and Zucchelli, 1996, Muller et al., 1998), and the present paper may be regarded as a further contribution to this discussion. It is due to the immediate clinical relevance of the topic, that a multitude of studies has already taken up some of this issue's many facets: How thick is the marginal gingiva above the formerly exposed root surface after surgical root coverage either with or without CTG application? Does an increased thickness of the root covering soft tissues improve the treatment outcome? Is there any correlation between marginal soft tissue thickness and the stability of the gingival margin's position over time?

Although the evidence in the published literature has shown that the combined procedure with the additional use of an autologous CTG is the most effective and predictable surgical approach for covering gingival recession defects (Chambrone et al., 2008, Cortellini and Pini Prato, 2012), most of the aforementioned questions still have remained unanswered to this day. Two principal reasons may be given to explain this lack of knowledge: even though numerous more studies have addressed and discussed the issue, very few investigations have actually attempted to measure or quantify soft tissue thickness in connection with surgical root coverage. Moreover, just one, very recently published study has actually attempted to examine the relationship between the measured soft tissue thickness and the achieved root coverage by means of a statistical analysis (Ahmedbeyli et al., 2014). Beyond that, none of the few available studies reporting on long-term outcomes after surgical root coverage has ever measured soft tissue thickness in the long run (Zucchelli and De Sanctis, 2005, Nickles et al., 2010, Pini-Prato et al., 2010, McGuire et al., 2012) - instead of that, it has been taken for granted many times that any successful short-term thickening of the marginal tissues will also show long-term stability. However, it still remains unclear at the moment whether this is indeed the case and which consequences this might have with regard to the stability of the gingival margin.

Periodontal literature provides evidence of a variety of different technique-related prognostic factors that have an influence on the outcome of root-coverage procedures, the use of a CTG just being one of them (Cortellini and Pini Prato, 2012). With regard to the clinical approaches of the present trial, relevant aspects of the surgical proceeding, and in particular flap design, were already discussed in the first part of this article series (Zuhr et al., 2013). In this context, it should be noted again that the very different surgical design of both procedures, being a tunnelling flap preparation in comparison to a CAF procedure with

This article is protected by copyright. All rights reserved. 
vertical releasing incisions, might at least in part serve as an explanation for the differences in the clinical outcomes between both groups (Zuhr et al., 2013). This second article's discussion is now, however, intended to be exclusively focused on the issue of the thickness of the root covering soft tissues.

Hitherto existing studies most commonly used diverse endodontic instruments or anaesthetic needles together with a silicone disc stop and a calliper in order to perform clinical measurements of marginal soft tissue thickness (Paolantonio et al., 2002, da Silva et al., 2004, Zucchelli et al., 2010, Cardaropoli et al., 2012, Jepsen et al., 2013). Some other investigations used ultrasonic devices (Muller et al., 1998, Muller et al., 1999). In the present study, a three-dimensional digital measuring method has been used for the first time in a clinical trial to evaluate the outcomes after surgical root coverage (Zuhr et al., 2013). This recently developed innovative method has been originally described to measure in vitro imitated alveolar ridge defects (Windisch et al., 2007), and has since been successfully adopted in a variety of experimental and clinical studies to record soft-tissue contour and volume changes in a diverse range of clinical scenarios (Fickl et al., 2009, Strebel et al., 2009, Thoma et al., 2010, Schneider et al., 2011). Recent methodological studies then also validated and suggested its use for the measurement of gingival recession like defects (Lehmann et al., 2012, Schneider et al., 2013). In this context, by comparing pre- versus post-operative soft-tissue contour lines, the applied technique does not only allow to measure soft-tissue volume changes but also to quantify the thickness of the marginal soft tissues that have been surgically established above the formerly exposed root surfaces. The method offers some great advantages including its non-invasive character as well as a high reproducibility and an excellent accuracy of measurements (Windisch et al., 2007, Lehmann et al., 2012, Schneider et al., 2013). It uses a digital ruler with a highly graduated scale, which enables to perform linear measurements to the nearest $0.01 \mathrm{~mm}$ - as a consequence, no rounding error occurs, as it needs to be accepted for conventional measurements. In doing so, this method provides a previously unforeseen precision in the evaluation of surgical root coverage outcomes with regard to both two-dimensional (recession depth) measurements as well as three-dimensional (soft tissue thickness / volumetric) evaluations. Admittedly, the applied measuring technique implies one limitation: as measurements are based on the evaluation of soft tissue contour changes over time, it is not possible, however, to quantify the pre-operative marginal soft tissue thickness but only post-operative values.

Coming to the clinical findings of the present study, the measured mean marginal soft tissue thickness (THK) after 12 months was $0.91 \mathrm{~mm}$ at sites having received CAF treatment. In contrast to that, the corresponding value in the TUN group amounted to $1.63 \mathrm{~mm}$. The measured difference for this comparison was statistically significant. At this point, however, it

This article is protected by copyright. All rights reserved. 
is important to remember the above-mentioned limitation of the applied measuring technique, which disallowed any pre-operative measurement of marginal soft tissue thickness. Since it is not possible to verify a balanced allocation of pre-operative thickness values between both groups, it is therefore, from a clinical point of view, just a reasonable speculation that the additional amount of around $0.70 \mathrm{~mm}$ at TUN-treated sites reflects, at least in large parts, the result of a successful thickening of the marginal tissues due to the use of a CTG. Having this limitation in mind, and also considering that the use of a new measuring technique impairs any comparison to previous studies, the present data are, however, quite in accordance to the few available data in the published literature. In one of the very first studies evaluating marginal soft tissue thickness, Müller et al. investigated the outcomes following surgical root coverage with free connective tissue grafts (Muller et al., 1998). Using a special ultrasonic device for their measurements, the authors were able to document in a series of consecutively treated cases a mean increase in marginal soft tissue thickness from 0.83 to $1.51 \mathrm{~mm}$ after 12 months. In a RCT, da Silva et al. compared a CAF procedure either alone or in conjunction with a CTG in the treatment of gingival recession defects (da Silva et al., 2004). Soft tissue thickness was evaluated with the use of an endodontic instrument and a calliper. While the measured thickness between pre- and post-operative conditions remained virtually constant at sites treated with CAF alone $(1.27 \mathrm{~mm}$ pre-operative vs. $1.28 \mathrm{~mm}$ postoperative), a mean increase of $0.44 \mathrm{~mm}$ after 6 months was recorded for the group treated with the combined approach $(1.34 \mathrm{~mm}$ vs. $1.78 \mathrm{~mm})$. In another comparative study, Paolantonio et al. reported on a successful increase of marginal soft tissue thickness from 0.81 to $1.96 \mathrm{~mm}$ after 12 months for a bilaminar technique with CTG (Paolantonio et al., 2002). Lastly, there are a few more recently published articles which provide some data of soft tissue thickness measurements in connection with surgical root coverage: Cardaropoli et al. $(0.93 \mathrm{~mm}$ vs. $1.1 \mathrm{~mm})$ as well as Jepsen et al. $(0.89 \mathrm{~mm}$ vs. $1.23 \mathrm{~mm})$ both reported on a constant or slightly increased gingival thickness 6 months after surgical root coverage with a CAF alone (Cardaropoli and Cardaropoli, 2009, Jepsen et al., 2013). And Zucchelli et al. ( $0.71 \mathrm{~mm}$ vs. $1.32 \mathrm{~mm} ; 0.75 \mathrm{~mm}$ vs. $1.55 \mathrm{~mm}$ ) as well as Cardaropoli et al. (0.86 mm vs. $2.09 \mathrm{~mm}$ ) were able to demonstrate a more or less considerably increased gingival thickness following 12 months after surgical root coverage with a combined approach of CAF with CTGs (Zucchelli et al., 2010, Cardaropoli et al., 2012). Summarizing the results of the aforecited studies and comparing them to the post-operative values of gingival thickness measured in the present investigation, it may be concluded that the combined approach with the use of a CTG is a successful measure to augment the soft tissues and thus to increase gingival thickness, at least in the short term with the longest documented follow-up period currently being 12 months. The published data of the combined procedure show a high degree of variability with regard to the post-operatively measured thicknesses, which is most

This article is protected by copyright. All rights reserved. 
probably related to differences in the size of the grafts as well as in the quality or rather histologic composition (as a consequence of the donor site) of the grafts used in different investigations (Zucchelli et al., 2010, Zuhr et al., in press). When, on the other hand, surgical root coverage is performed without any additional augmentation of the soft tissues, the thickness of the root covering tissues seems mainly to be influenced by the thickness of the elevated flap as a consequence of the pre-existing gingival dimensions and thus the gingival biotype. According to ultrasonic measurements performed in periodontally healthy subjects, the mean buccal gingival thickness varies in a range from 0.9 to $1.3 \mathrm{~mm}$ for different tooth types in the anterior maxilla (Eger et al., 1996), which is well comparable to the postoperatively measured thicknesses following surgical root coverage with a CAF alone. However, it remains unclear to the moment to which extent details of the surgical proceeding, such as the design of the flap (i.e. split- vs. full-thickness preparation) or the adjunctive use of root surface-conditioning (e.g. enamel matrix derivative, as used in the present investigation), may have an influence on the thickness of the tissues surgically established above the formerly exposed root surfaces.

The published literature provides substantial evidence that the combined procedure with the additional use of a CTG shows the best clinical outcomes for both recession reduction and complete root coverage (Chambrone et al., 2008, Cortellini and Pini Prato, 2012). The real significance of using a CTG in root coverage procedures, however, has still not been entirely clarified. While some investigations noticed a reduced initial contraction of the soft tissues at sites treated with a CTG under the flap (Cortellini et al., 2009), which might be interpreted in a way that the presence of a graft may stabilize the gingival margin in its coronal position und thus serves as an "anchor" for the covering flap during the crucial phase of early wound healing, some other studies reported of a trend of the so-called "creeping attachment", which refers to a certain coronal shift of the gingival margin that was observed in grafted sites over time (Agudio et al., 2009, Pini-Prato et al., 2010). The data gained in the present investigation, however, identified post-operative gingival thickness to be a relevant prognostic factor for surgical root coverage: at 12 months, recession reduction as well as mean root coverage both were significantly better at CT-grafted sites treated in the TUN group (1.94 $\mathrm{mm}$ and $98.4 \%$, respectively) compared to the non-augmented sites of the CAF group (1.17 $\mathrm{mm}$ and $71.8 \%$, respectively), and statistical analysis of the study's complete data-set revealed a positive correlation of marginal soft tissue thickness to both these variables. In other words: the use of a CTG appeared to be a successful measure to increase marginal soft tissue thickness and this led to improved outcomes with regard to the amount of surgical root coverage, at least for this study's follow-up period of 12 months. This is quite

This article is protected by copyright. All rights reserved. 
in accordance with a very recently published investigation of Ahmedbeyli et al. who compared a CAF procedure either alone or in conjunction with an acellular dermal matrix graft in the treatment of multiple gingival recession defects (Ahmedbeyli et al., 2014). The authors found a significant positive correlation between gingival thickness and mean defect coverage after 12 months. On the other hand, however, the data of the present experiment also indicated that exceeding a certain soft tissue thickness was not worthwhile with regard to the surgical outcome. Following statistical analysis using a logistic model, a mean marginal soft tissue thickness of $1.44 \mathrm{~mm}$ was calculated to be necessary for achieving CRC in the patient population of the present study. This value is slightly above the aforementioned range of mean gingival thicknesses measured in the anterior maxilla of periodontally healthy subjects $(0.9$ to $1.3 \mathrm{~mm}$ ) (Eger et al., 1996), which particularly suggests that situations of thinner tissue biotypes seem to benefit from some minor gingival thickening during surgical root coverage. In this respect, the present data appear in line with some recently published recommendations on clinical decision-making, which encourage the use of rather reasonably sized, thin CTGs in gingival recession treatment (Zucchelli et al., 2003, Cortellini and Pini Prato, 2012). In the same way, the present findings may also seem to underscore the hypothesis of many experts that CAF alone can be successfully applied in clinical situations where the residual gingiva is rather thick and wide (Cortellini and Pini Prato, 2012).

In a cohort of 6 TUN-treated patients, healing dynamics at CT-grafted sites were evaluated by means of volumetric observations. The gathered data revealed that the grafts used in this study (having been harvested from the lateral anterior palate) were subject to considerable post-operative volumetric alterations. Soft tissue volume changes, and thus the healing process, seemed to be accomplished after 6 months. This information is of considerable clinical relevance when it comes, for instance, to the decision when to proceed with prosthetic treatment after pre-prosthetic plastic-periodontal surgery has been carried out. Furthermore in detail, it could be shown that treated sites underwent a mean shrinkage of $1 / 4$ of the augmented volume after 3 months, amounting to $1 / 3$ after 12 months - this corresponded to a mean maintenance of $74 \%$ of the augmented volume after 3 months and $64 \%$ after 12 months, respectively.

In one previous clinical study, Studer et al. used different autologous CTGs to treat singletooth ridge defects (Studer et al., 2000). The authors were able to document a successful augmentation of the soft tissues by measuring volumetric changes with an optical projection Moiré method. Though, the treated patients were only followed for 3.5 months, so that the present study provides documentation of a clinical soft tissue volume augmentation over a

This article is protected by copyright. All rights reserved. 
considerably prolonged follow-up period of 12 months. However, there is one shortcoming regarding the measurements in both the afore-cited as well as in the present study, as volumetric evaluations in both studies were based on optical scans of study models. To this purpose, impressions of the experimental sites were made at different time-points, which made it impossible to gain any information of the immediate post-operative situation of the sites. Therefore, in order to allow for any statement regarding the amount of post-operative shrinkage at grafted sites in the present study, the volume gain measured 1 month after surgery was regarded as the baseline value of soft tissue augmentation. It may be assumed that most of the post-operative swelling had resolved as well as not too much of postoperative shrinkage had yet occurred 1 month after surgery - however, future investigations will probably overcome this inaccuracy, as ongoing research with this three-dimensional measuring method is aiming to introduce direct intra-oral optical scans that might one day allow to capture freshly operated sites, too.

The findings of this study suggest that especially sites of thinner gingival biotypes seem to benefit from some minor gingival thickening during surgical root coverage, aiming for a mean marginal soft tissue thickness of around $1.5 \mathrm{~mm}$ after surgery. With the knowledge from the present volumetric studies in mind, indicating that grafted sites will experience a prudently estimated volumetric shrinkage of around $1 / 3$ of the volume augmented with a graft from the lateral palate, the recommendation for the use of reasonably-sized, tendentious thinner grafts appears to be well in accordance with Zucchelli et al. who supposed that small-sized and rather thin grafts could enhance the nutritional exchange between the recipient site, graft and covering flap and also lead to better esthetic outcomes (Zucchelli et al., 2003). In a randomized clinical trial, the authors compared the bilaminar approach with conventional graft dimensions to the use of smaller-sized and thinner grafts with a thickness of about 1 $\mathrm{mm}$ (the grafts were both harvested from the lateral palate). Outcomes were similar with regard to root coverage, but esthetics and patient perception were much more favourable in sites treated with the smaller grafts. Regarding patient perception, questionnaires were used in the present study to evaluate patient-centered outcomes, too (Zuhr et al., 2013). Besides some pre-formulated questions, patients were also encouraged to make free comments in the questionnaire. In doing so, two TUN-treated patients reported on an unpleasant postoperative thickness of the gingival tissues. Interestingly, volumetric analysis now revealed that these comments related to the two cases with the greatest post-operative thickness of all patients in the study, showing the only values of mean marginal soft tissue thickness above 2 $\mathrm{mm}$.

This article is protected by copyright. All rights reserved. 
This article reports about the 1-year results of this investigation. Thus any statement on the beneficial role of increased gingival thickness with regard to the long-term stability of the gingival margin is rather speculative, but a long-term follow-up of the present patient population is intended. In future research the broad use of a further developed version of this measuring technique (particularly incorporating a direct intra-oral optical scanner) would be desirable, aiming to investigate the clinical performance of autologous CTGs deriving from different donor sites as well as the emerging field of connective tissue substitutes (Zuhr et al., in press).

Within the limits of this study, the following conclusions can be drawn:

- The applied measuring method offers new perspectives in the evaluation of the outcomes after surgical recession treatment.

- TUN with CTG resulted in thicker gingiva and in better root coverage compared to CAF with EMD.

- Increased gingival thickness was associated with better surgical outcomes in terms of recession reduction and root coverage.

- Soft tissue healing following surgical root coverage with CT grafting was mainly accomplished after 6 months, with around $2 / 3$ of the augmented volume being maintained after 12 months.

\section{ACKNOWLEDGEMENTS}

The authors gratefully acknowledge Dr. Ali Daouk (Private Practice, Obertshausen, Germany) and Franz Rebele (Private Practice, Dinkelsbühl, Germany) for their support with patient recruitment. They would also like to thank Kirstin Vach (Institute of Medical Biometry and Medical Informatics, Albert-Ludwigs-University, Freiburg, Germany) for her expertise and support in the statistical analysis.

\section{REFERENCES}

Agudio, G., Nieri, M., Rotundo, R., Franceschi, D., Cortellini, P. \& Pini Prato, G. P. (2009) Periodontal conditions of sites treated with gingival-augmentation surgery compared to untreated contralateral homologous sites: a 10- to 27-year long-term study. J Periodontol 80, 1399-1405. doi:10.1902/jop.2009.090122.

This article is protected by copyright. All rights reserved. 
Ahmedbeyli, C., Ipci, S. D., Cakar, G., Kuru, B. E. \& Yilmaz, S. (2014) Clinical evaluation of coronally advanced flap with or without acellular dermal matrix graft on complete defect coverage for the treatment of multiple gingival recessions with thin tissue biotype. J Clin Periodontol 41, 303-310. doi:10.1111/jcpe.12211.

Baldi, C., Pini-Prato, G., Pagliaro, U., Nieri, M., Saletta, D., Muzzi, L. \& Cortellini, P. (1999) Coronally advanced flap procedure for root coverage. Is flap thickness a relevant predictor to achieve root coverage? A 19-case series. J Periodontol 70, 1077-1084. doi:10.1902/jop.1999.70.9.1077.

Cairo, F., Pagliaro, U. \& Nieri, M. (2008) Treatment of gingival recession with coronally advanced flap procedures: a systematic review. J Clin Periodontol 35, 136-162. doi:10.1111/j.1600051X.2008.01267.x.

Cardaropoli, D. \& Cardaropoli, G. (2009) Healing of gingival recessions using a collagen membrane with a hemineralized xenograft: a randomized controlled clinical trial. Int J Periodontics Restorative Dent 29, 59-67.

Cardaropoli, D., Tamagnone, L., Roffredo, A. \& Gaveglio, L. (2012) Treatment of gingival recession defects using coronally advanced flap with a porcine collagen matrix compared to coronally advanced flap with connective tissue graft: a rand omized controlled clinical trial. J Periodontol 83, 321-328. doi:10.1902/jop.2011.110215.

Chambrone, L., Chambrone, D., Pustiglioni, F. E., Chambrone, L. A. \& Lima, L. A. (2008) Can subepithelial connective tissue grafts be considered the gold standard procedure in the treatment of Miller Class I and II recession-type defects? J Dent 36, 659-671. doi:10.1016/j.jdent.2008.05.007.

Chambrone, L., Sukekava, F., Araujo, M. G., Pustiglioni, F. E., Chambrone, L. A. \& Lima, L. A. (2010) Root-coverage procedures for the treatment of localized recession-type defects: a Cochrane systematic review. J Periodontol 81, 452-478. doi:10.1902/jop.2010.090540.

Cortellini, P. \& Pini Prato, G. (2012) Coronally advanced flap and combination therapy for root coverage. Clinical strategies based on scientific evidence and clinical experience. Periodontol 2000 59, 158-184. doi:10.1111/j.1600-0757.2011.00434.x.

Cortellini, P., Tonetti, M., Baldi, C., Francetti, L., Rasperini, G., Rotundo, R., Nieri, M., Franceschi, D., Labriola, A. \& Prato, G. P. (2009) Does placement of a connective tissue graft improve the outcomes of coronally advanced flap for coverage of single gingival recessions in upper anterior teeth? A multi-centre, randomized, double-blind, clinical trial. J Clin Periodontol 36, 68-79. doi:10.1111/j.1600-051X.2008.01346.x.

da Silva, R. C., Joly, J. C., de Lima, A. F. \& Tatakis, D. N. (2004) Root coverage using the coronally positioned flap with or without a subepithelial connective tissue graft.J Periodontol 75, 413-419. doi:10.1902/jop.2004.75.3.413.

Eger, T., Muller, H. P. \& Heinecke, A. (1996) Ultrasonic determination of gingival thickness. Subject variation and influence of tooth type and clinical features. J Clin Periodontol 23, 839-845.

This article is protected by copyright. All rights reserved. 
Fickl, S., Schneider, D., Zuhr, O., Hinze, M., Ender, A., Jung, R. E. \& Hurzeler, M. B. (2009) Dimensional changes of the ridge contour after socket preservation and buccal overbuilding: an animal study. J Clin Periodontol 36, 442-448. doi:10.1111/j.1600051X.2009.01381.X.

Hwang, D. \& Wang, H. L. (2006) Flap thickness as a predictor of root coverage: a systematic review. J Periodontol 77, 1625-1634. doi:10.1902/jop.2006.060107.

Jepsen, K., Jepsen, S., Zucchelli, G., Stefanini, M., de Sanctis, M., Baldini, N., Greven, B., Heinz, B., Wennstrom, J., Cassel, B., Vignoletti, F. \& Sanz, M. (2013) Treatment of gingival recession defects with a coronally advanced flap and a xenogeneic collagen matrix: a multicenter randomized clinical trial. J Clin Periodontol 40, 82-89. doi:10.1111/jcpe.12019.

Lehmann, K. M., Kasaj, A., Ross, A., Kammerer, P. W., Wagner, W. \& Scheller, H. (2012) A new method for volumetric evaluation of gingival recessions: a feasibility study. J Periodontol 83, 50-54. doi:10.1902/jop.2011.110143.

McGuire, M. K., Scheyer, E. T. \& Nunn, M. (2012) Evaluation of human recession defects treated with coronally advanced flaps and either enamel matrix derivative or connective tissue: comparison of clinical parameters at 10 years. J Periodontol 83, 1353-1362. doi:10.1902/jop.2012.110373.

Miller, P. D., Jr. (1985) A classification of marginal tissue recession. Int J Periodontics Restorative Dent 5, 8-13.

Moher, D., Hopewell, S., Schulz, K. F., Montori, V., Gotzsche, P. C., Devereaux, P. J., Elbourne, D., Egger, M. \& Altman, D. G. (2010) CONSORT 2010 explanation and elaboration: updated guidelines for reporting parallel group randomised trials. BMJ 340, c869. doi:10.1136/bmj.c869.

Muller, H. P., Eger, T. \& Schorb, A. (1998) Gingival dimensions after root coverage with free connective tissue grafts. J Clin Periodontol 25, 424-430.

Muller, H. P., Stahl, M. \& Eger, T. (1999) Root coverage employing an envelope technique or guided tissue regeneration with a bioabsorbable membrane. J Periodontol 70, 743-751. doi:10.1902/jop.1999.70.7.743.

Nickles, K., Ratka-Kruger, P., Neukranz, E., Raetzke, P. \& Eickholz, P. (2010) Ten-year results after connective tissue grafts and guided tissue regeneration for root coverage. $J$ Periodontol 81, 827-836. doi:10.1902/jop.2010.090632.

Paolantonio, M., Dolci, M., Esposito, P., D'Archivio, D., Lisanti, L., Di Luccio, A. \& Perinetti, G. (2002) Subpedicle acellular dermal matrix graft and autogenous connective tissue graft in the treatment of gingival recessions: a comparative 1-year clinical study. J Periodontol 73, 1299-1307. doi:10.1902/jop.2002.73.11.1299.

Pini-Prato, G. P., Cairo, F., Nieri, M., Franceschi, D., Rotundo, R. \& Cortellini, P. (2010) Coronally advanced flap versus connective tissue graft in the treatment of multiple gingival recessions: a split-mouth study with a 5-year follow-up. J Clin Periodontol 37, 644-650. doi:10.1111/j.1600-051X.2010.01559.x.

This article is protected by copyright. All rights reserved. 
Schneider, D., Ender, A., Truninger, T., Leutert, C., Sahrmann, P., Roos, M. \& Schmidlin, P. (2013) Comparison between Clinical and Digital Soft Tissue Measurements. J Esthet Restor Dent. doi:10.1111/jerd.12084.

Schneider, D., Grunder, U., Ender, A., Hammerle, C. H. \& Jung, R. E. (2011) Volume gain and stability of peri-implant tissue following bone and soft tissue augmentation: 1-year results from a prospective cohort study. Clin Oral Implants Res 22, 28-37. doi:10.1111/j.1600-0501.2010.01987.x.

Schulz, K. F., Altman, D. G., Moher, D. \& Group, C. (2010) CONSORT 2010 statement: updated guidelines for reporting parallel group randomised trials. BMJ 340, c332. doi:10.1136/bmj.c332.

Strebel, J., Ender, A., Paque, F., Krahenmann, M., Attin, T. \& Schmidlin, P. R. (2009) In vivo validation of a three-dimensional optical method to document volumetric soft tissue changes of the interdental papilla. J Periodontol 80, 56-61. doi:10.1902/jop.2009.080288.

Studer, S. P., Lehner, C., Bucher, A. \& Scharer, P. (2000) Soft tissue correction of a single-tooth pontic space: a comparative quantitative volume assessment. J Prosthet Dent 83, 402411.

Thoma, D. S., Jung, R. E., Schneider, D., Cochran, D. L., Ender, A., Jones, A. A., Gorlach, C., Uebersax, L., Graf-Hausner, U. \& Hammerle, C. H. (2010) Soft tissue volume augmentation by the use of collagen-based matrices: a volumetric analysis. J Clin Periodontol 37, 659-666. doi:10.1111/j.1600-051X.2010.01581.x.

Wennstrom, J. L. \& Zucchelli, G. (1996) Increased gingival dimensions. A significant factor for successful outcome of root coverage procedures? A 2-year prospective clinical study. $J$ Clin Periodontol 23, 770-777.

Windisch, S. I., Jung, R. E., Sailer, I., Studer, S. P., Ender, A. \& Hammerle, C. H. (2007) A new optical method to evaluate three-dimensional volume changes of alveolar contours: a methodological in vitro study. Clin Oral Implants Res 18, 545-551. doi:10.1111/j.16000501.2007.01382.x.

Zucchelli, G., Amore, C., Sforza, N. M., Montebugnoli, L. \& De Sanctis, M. (2003) Bilaminar techniques for the treatment of recession-type defects. A comparative clinical study. $J$ Clin Periodontol 30, 862-870.

Zucchelli, G. \& De Sanctis, M. (2005) Long-term outcome following treatment of multiple Miller class I and II recession defects in esthetic areas of the mouth. J Periodontol 76, 22862292. doi:10.1902/jop.2005.76.12.2286.

Zucchelli, G., Mele, M., Stefanini, M., Mazzotti, C., Marzadori, M., Montebugnoli, L. \& de Sanctis, M. (2010) Patient morbidity and root coverage outcome after subepithelial connective tissue and de-epithelialized grafts: a comparative randomized-controlled clinical trial. $J$ Clin Periodontol 37, 728-738. doi:10.1111/j.1600-051X.2010.01550.x.

This article is protected by copyright. All rights reserved. 
Zuhr, O., Baumer, D. \& Hurzeler, M. (in press) The addition of soft tissue replacement grafts in plastic periodontal and implant surgery: critical elements in design and execution. J Clin Periodontol.

Zuhr, O., Fickl, S., Wachtel, H., Bolz, W. \& Hurzeler, M. B. (2007) Covering of gingival recessions with a modified microsurgical tunnel technique: case report. Int J Periodontics Restorative Dent 27, 457-463.

Zuhr, O., Rebele, S. F., Schneider, D., Jung, R. E. \& Hurzeler, M. B. (2013) Tunnel technique with connective tissue graft versus coronally advanced flap with enamel matrix derivative for root coverage: a RCT using 3D digital measuring methods. Part I. Clinical and patientcentred outcomes. J Clin Periodontol. doi:10.1111/jcpe.12178.

Zuhr, O., Rebele, S. F., Thalmair, T., Fickl, S. \& Hurzeler, M. B. (2009) A modified suture technique for plastic periodontal and implant surgery--the double-crossed suture. Eur J Esthet Dent 4, 338-347.

Table 1. Recession depth $(\mathrm{mm})$ and marginal soft tissue thickness $(\mathrm{mm})$ at baseline, 6 and 12 months

\begin{tabular}{|c|c|c|c|}
\hline & \multicolumn{3}{|c|}{ Recession depth (REC) } \\
\hline & TUN & CAF & $p$-value \\
\hline Baseline & $1.93 \pm 0.57$ & $1.69 \pm 0.63$ & 0.1776 \\
\hline 6 months & $0.02 \pm 0.05$ & $0.53 \pm 0.47$ & 0.0001 \\
\hline \multirow[t]{3}{*}{12 months } & $0.04 \pm 0.07$ & $0.55 \pm 0.49$ & 0.0004 \\
\hline & \multicolumn{3}{|c|}{ Marginal soft tissue thickness (THK) } \\
\hline & TUN & CAF & $p$-value \\
\hline 6 months & $1.69 \pm 0.40$ & $0.90 \pm 0.18$ & $<0.0001$ \\
\hline 12 months & $1.63 \pm 0.42$ & $0.91 \pm 0.18$ & $<0.0001$ \\
\hline
\end{tabular}

This article is protected by copyright. All rights reserved. 
Table 2. Comparison of TUN and CAF for variables of recession depth reduction $(\mathrm{mm}), \%$ root coverage and \% defects with complete root coverage 6 and 12 months after surgery

\begin{tabular}{|c|c|c|c|c|c|c|}
\hline & \multicolumn{3}{|c|}{ baseline -6 months } & \multicolumn{3}{|c|}{ baseline -12 months } \\
\hline & TUN & $\mathrm{CAF}$ & $p$-value & TUN & $\mathrm{CAF}$ & $p$-value \\
\hline $\begin{array}{l}\text { Recession depth (REC) } \\
\text { reduction }\end{array}$ & $\begin{array}{l}1.91 \pm \\
0.56\end{array}$ & $\begin{array}{l}1.21 \pm \\
0.46\end{array}$ & 0.0032 & $\begin{array}{c}1.94 \pm \\
0.57\end{array}$ & $\begin{array}{c}1.17 \pm \\
0.42\end{array}$ & 0.0015 \\
\hline$\%$ Root Coverage (RC) & $\begin{array}{c}99.2 \pm \\
1.6\end{array}$ & $\begin{array}{c}72.2 \pm \\
18.4\end{array}$ & 0.0001 & $\begin{array}{c}98.4 \pm \\
3.6\end{array}$ & $\begin{array}{l}71.8 \pm \\
20.3\end{array}$ & 0.0004 \\
\hline $\begin{array}{l}\text { \% Defects with complete root } \\
\text { coverage (CRC) }\end{array}$ & 80.0 & 15.4 & 0.002 & 78.6 & 21.4 & 0.007 \\
\hline
\end{tabular}

Table 3. Descriptive statistics with absolute $\left(\mathrm{mm}^{3}\right)$ and relative (\%) values of volumetric alterations in a cohort of 6 patients following CT grafting at TUN-treated sites

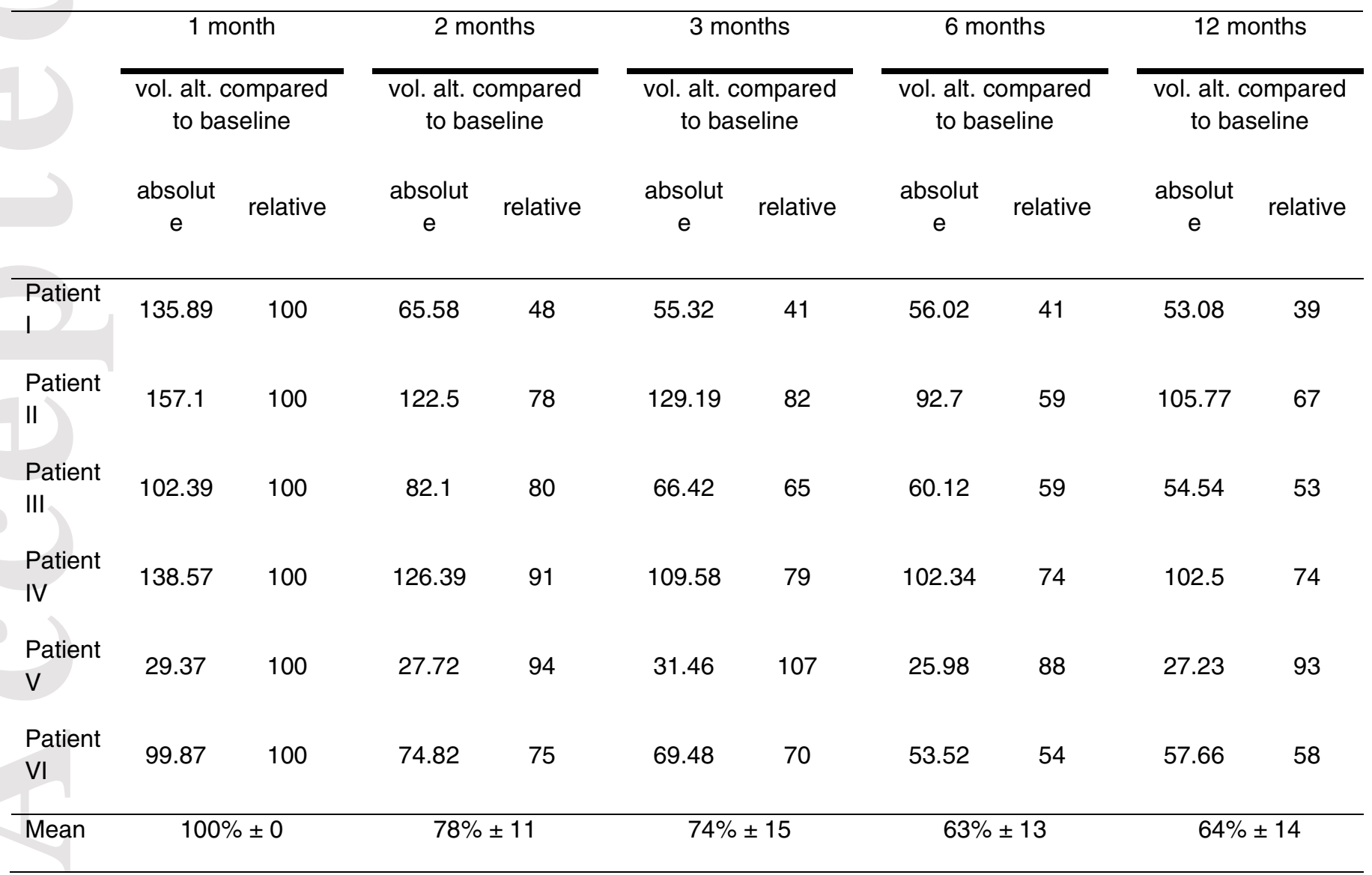

This article is protected by copyright. All rights reserved. 


\section{FIGURE LEGENDS}

Fig. 1 (a) Baseline view of a single recession defect on a right lateral incisor, which was randomly assigned to the TUN group. (b) 12-month follow-up of the case. (c) Frontal and (d) lateral view of the digital model gained through virtual superimposing of baseline and 12-month follow-up scans of this case. (e) While REC was measured in a cross-section at the central buccal site of the virtual tooth surface, (f) THK was measured in an individually defined area of interest above the formerly exposed root surface.

Table 1 Recession depth $(\mathrm{mm})$ and marginal soft tissue thickness $(\mathrm{mm})$ at baseline, 6 and 12 months

Table 2 Comparison of TUN and CAF for variables of recession depth reduction (mm), \% root coverage and \% defects with complete root coverage 6 and 12 months after surgery

Fig. 2 Scatter plot of mean marginal soft tissue thickness versus recession reduction after 12 months with fitted linear regression line.

Fig. 3 Scatter plot of mean marginal soft tissue thickness versus \% root coverage after 12 months with fitted logistic function (curve).

Table 3 Descriptive statistics with absolute $\left(\mathrm{mm}^{3}\right)$ and relative (\%) values of volumetric alterations in a cohort of 6 patients following CT grafting at

TUNtreated sites

Fig. 4 Plot of relative volumetric alterations in a cohort of 6 patients to visualize healing dynamics following CT grafting at TUN-treated sites.

This article is protected by copyright. All rights reserved. 

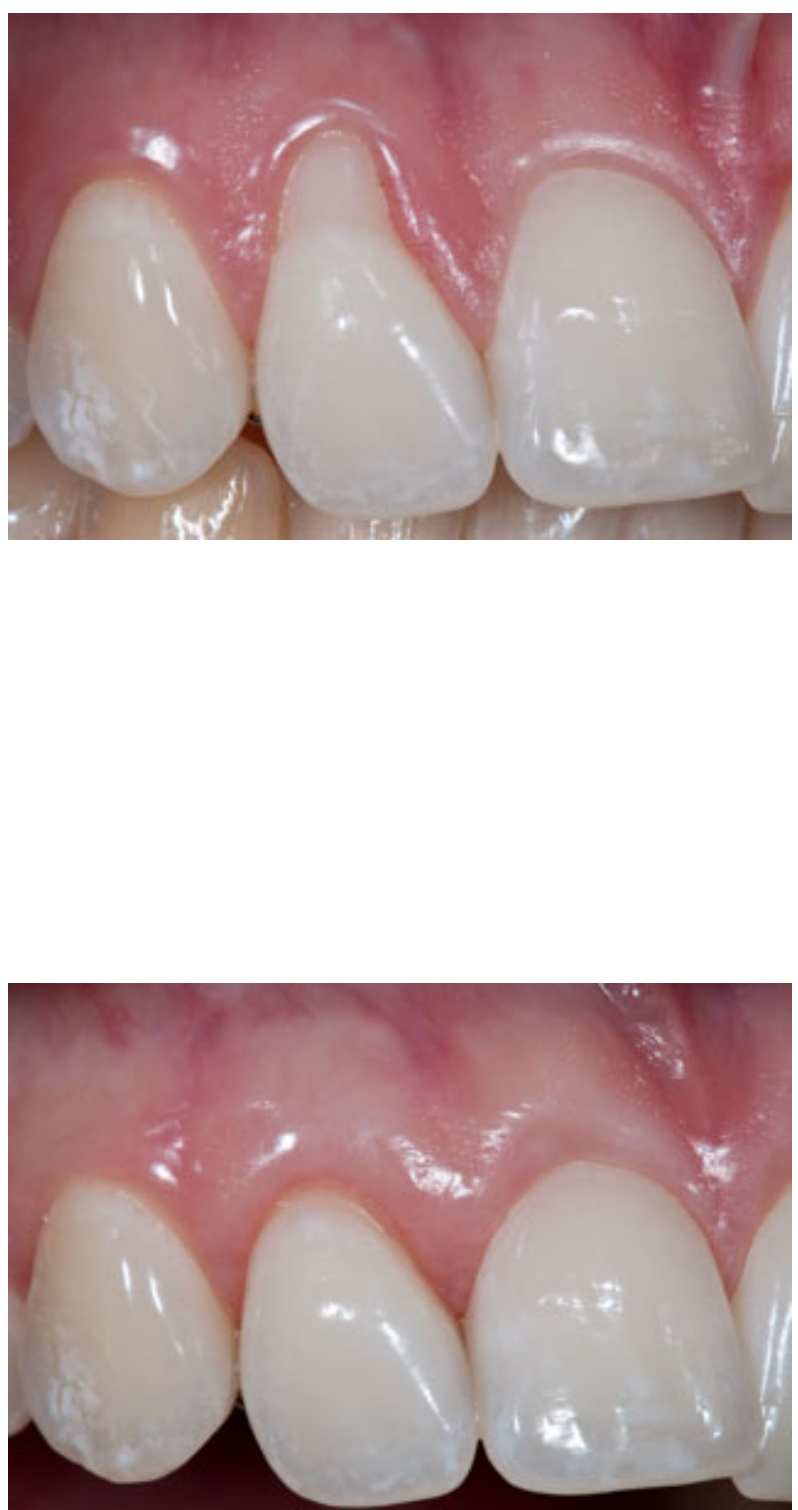

This article is protected by copyright. All rights reserved. 

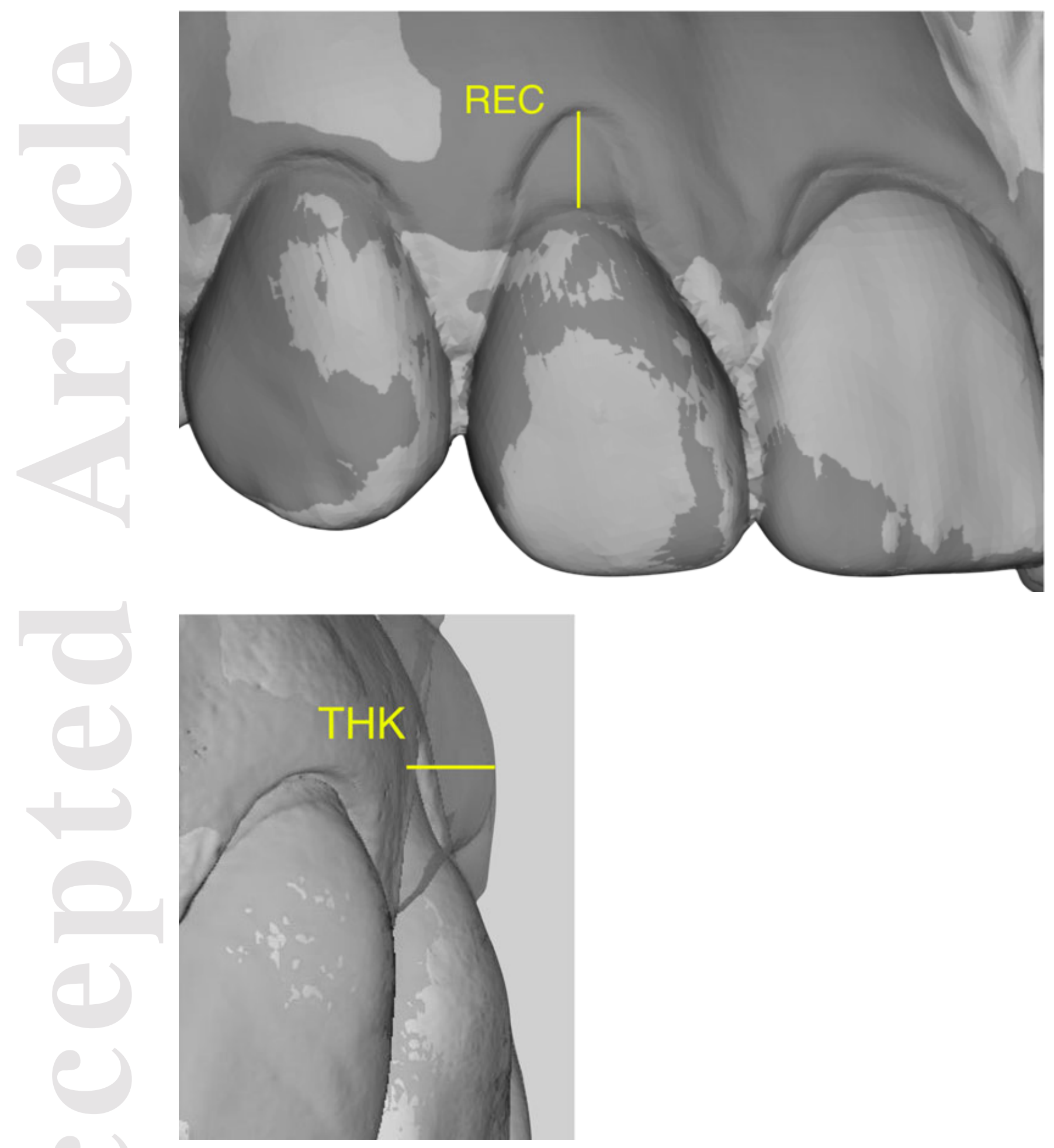

This article is protected by copyright. All rights reserved. 


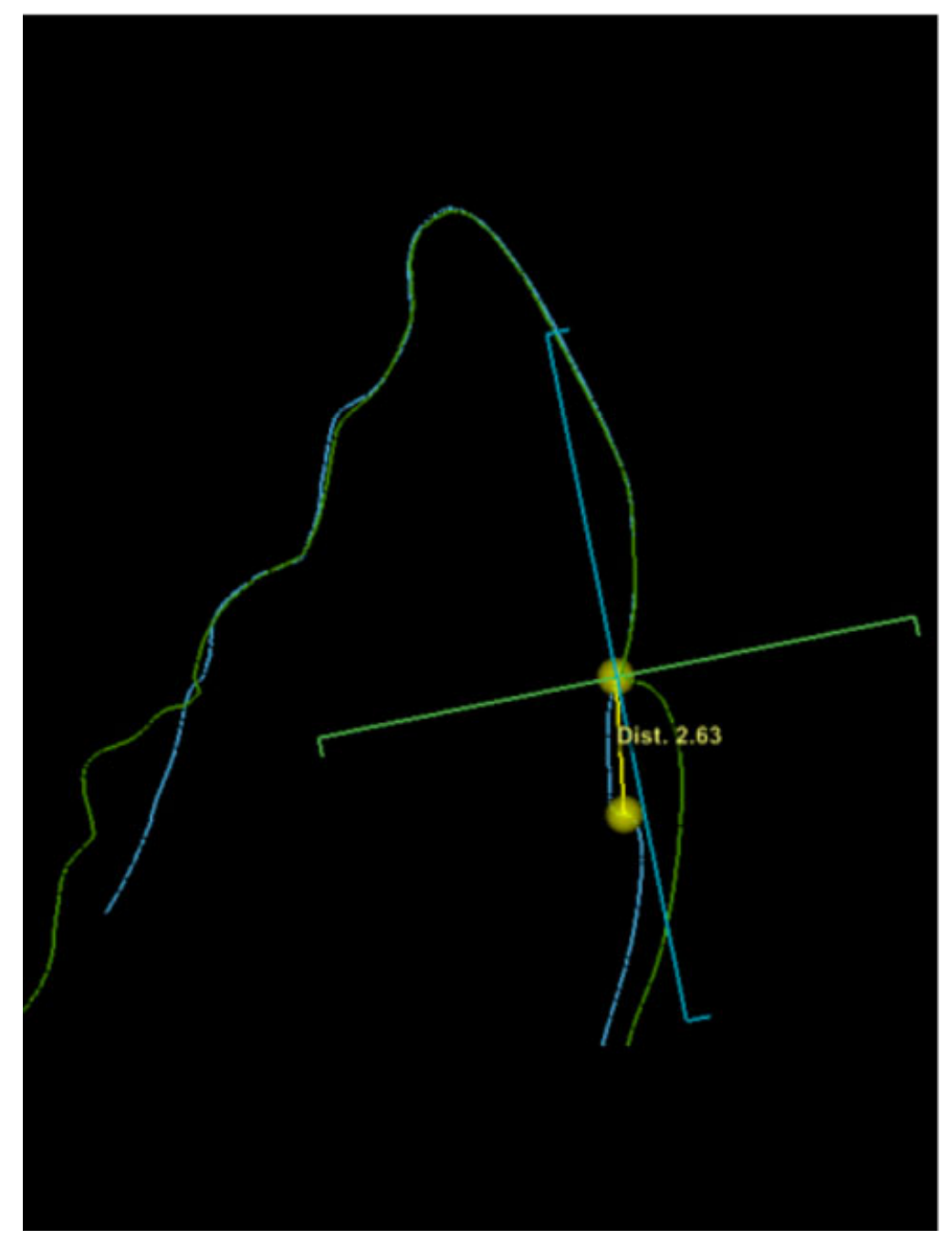

This article is protected by copyright. All rights reserved. 

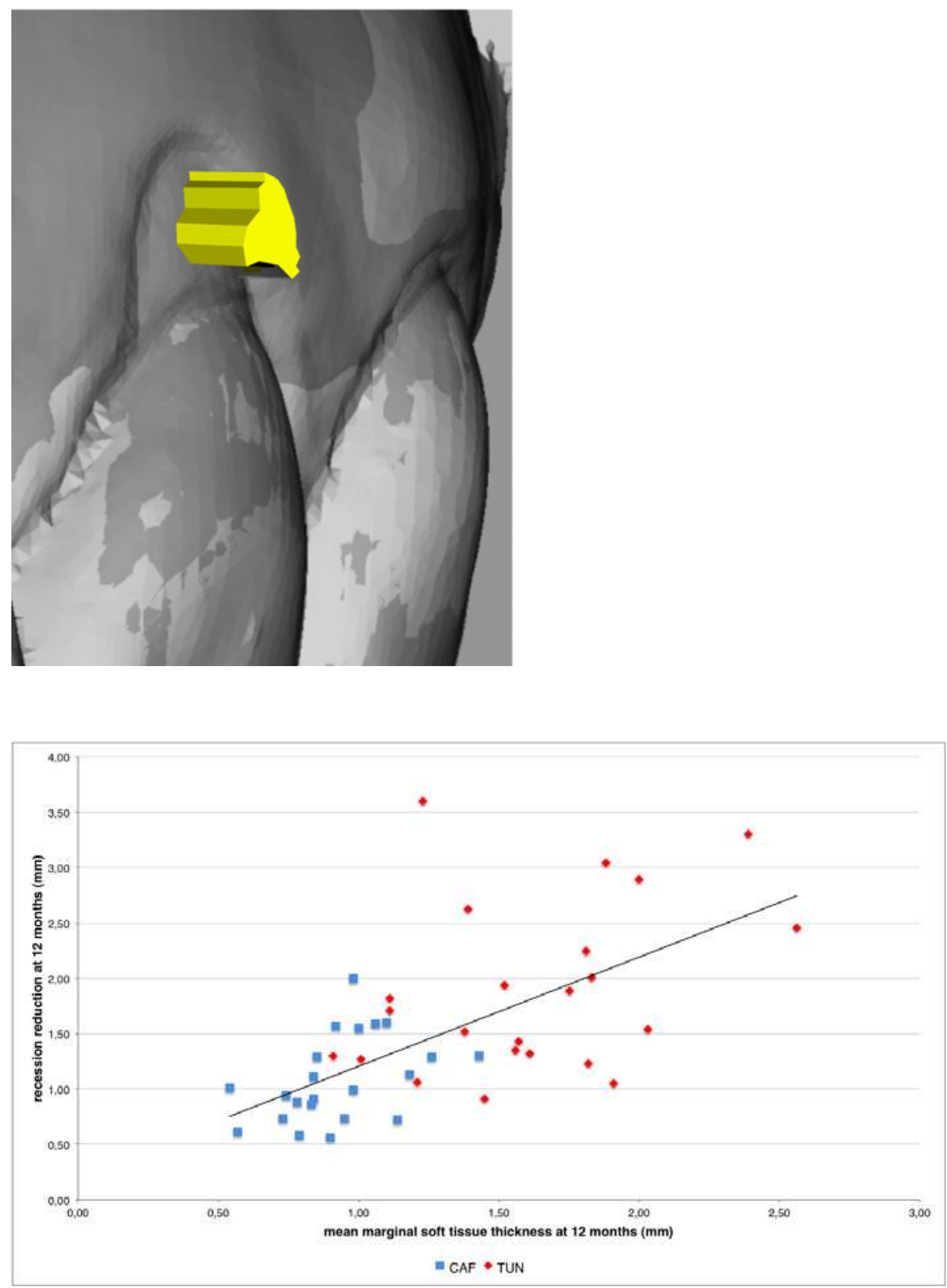

This article is protected by copyright. All rights reserved. 

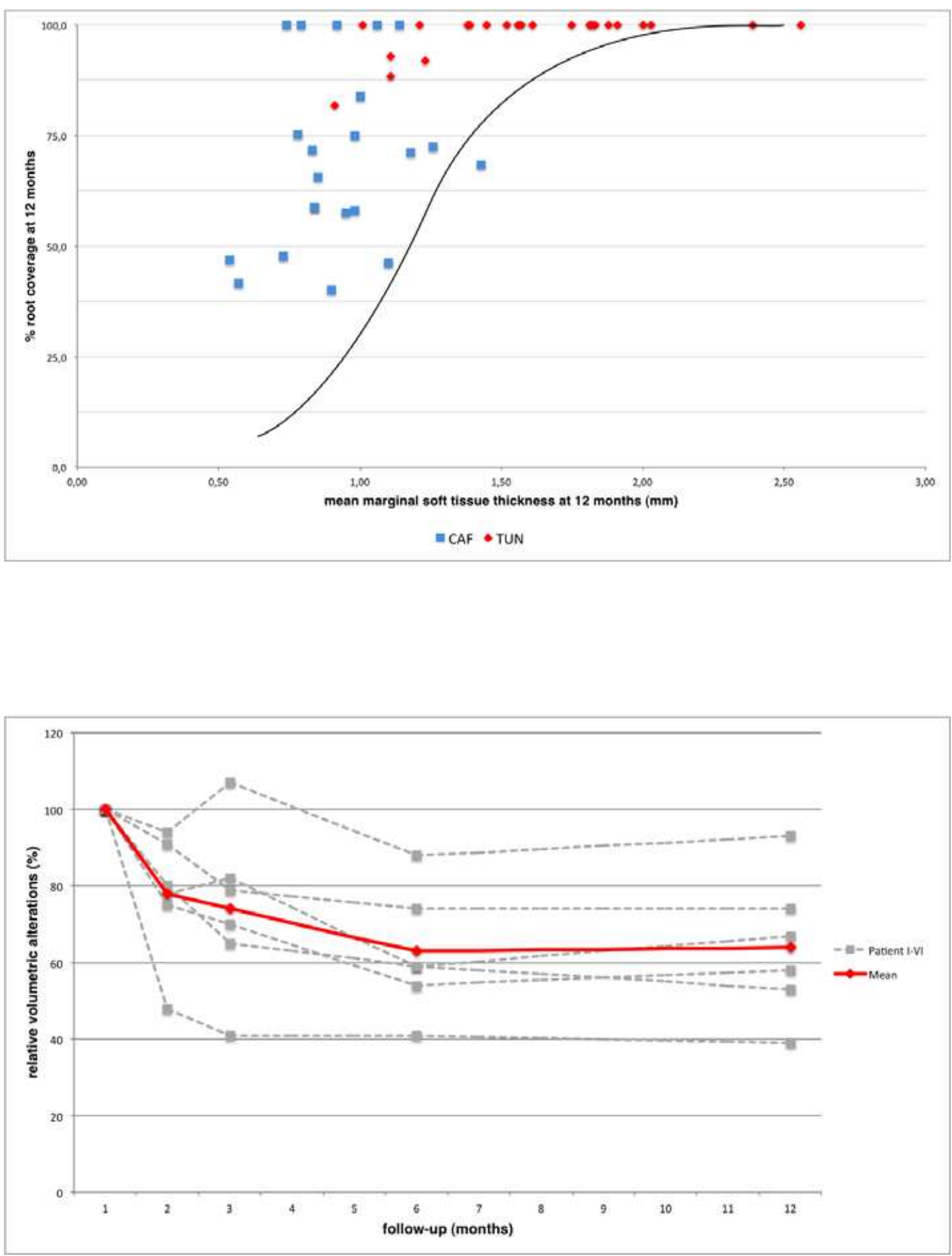

This article is protected by copyright. All rights reserved. 